\title{
A Cross-sectional Study to Evaluate Diabetes Management, Control and Complications in Patients with type 2 Diabetes in Bangladesh
}

\author{
Latif ZA ${ }^{\mathrm{a}}$, Ashrafuzzaman $\mathrm{SM}^{\mathrm{a}}$, Amin MF , Gadekar AV ${ }^{\mathrm{b}}$, Sobhan MJ' , Haider $\mathrm{T}^{\mathrm{c}}$
}

\begin{abstract}
Background: Management of type 2 diabetes is not uniform. The aim of the study was to assess diabetes care delivery and status of long-term diabetes related complications.

Methods: DiabCare is an observational, non-interventional, cross-sectional study of hospital-based outpatient type 2 diabetes care.

Results: A total of 2092 patients participated in the study: mean age $51.3 \pm 11.0$ years, and duration of diabetes $7.6 \pm 5.4$ years. The patients were almost equal in both genders (male: $49.8 \% \mathrm{vs}$. female: $50.2 \%$ ) and the largest homogenous ethnic group was Bangladeshi (99.6\%). The percentage of patients with $\mathrm{HbAlc}<7.0 \%(<53$ $\mathrm{mmol} / \mathrm{mol}$ ) was $22.5 \%$ and mean $\mathrm{HbAlc}$ was $8.8 \pm 2.2 \%$. The proportion of patients using insulin was $58.0 \%$ $(n=1214)$ at a total daily dose of $34.4 \pm 14.7$ IU. The most common diabetes related complications were: Peripheral neuropathy (39.0\%) and eye complications (21.7\%). Duration of diabetes was associated with higher odds of CV complications, diabetic nephropathy and eye complications [adjusted OR 1.03, $p=0.007$; 1.05, $p<0.001$ and 1.05, $p<0.001$ respectively]. Age also has emerged as a significant predictor for these complications. More than half of patients (56.1\%) indicated their concerns about hypoglycaemia. A large proportion of patients were non-adherent to clinical recommendations.

Conclusions: Poor glycaemic and metabolic control over a long period of time contributes to chronic diabetic complications. This underpins the need to further optimise the control strategies and maintain quality diabetes management standards in Bangladesh and also improving awareness among health professionals with intensive education programs for diabetes subjects is also recommended.
\end{abstract}

Key words: Diabetes mellitus, hospital care, prevention, diabetes complications, treatment adherence, hypoglycaemia

(BIRDEM Med J 2017; 7(1): 17-27)

\section{Introduction}

Estimates in 2015 indicate that approximately $8.5 \%$, equivalent to 78.3 million, of the adult population living in South East Asia (SEA) region suffer from type 2 diabetes mellitus

\footnotetext{
Author Informations

a. Dr. Zafar Ahmed Latif, SM Ashrafuzzaman, Mohammod Feroz Amin, BIRDEM Hospital, Dhaka, Bangladesh

b. Dr. Arvind Vilas Gadekar, Novo Nordisk Pharma Operations (BASEA), Kuala Lumpur, Malaysia

c. Dr. Md. Javed Sobhan, Tanvir Haider, Novo Nordisk, Bangladesh Address of Correspondence: Dr. Zafar Ahmed Latif, Director, BIRDEM Academy, E-mail: zaforalatif2011@yahoo.com

Received: October 18, 2015 Accepted: November 30, 2016
}

(T2DM). SEA region also witnessed $24.2 \%$ of all live births affected by high blood glucose during pregnancy. The projected increase of DM population in SEA, to 140.2 million by 2040 , is a major threat to public health resources. ${ }^{1,2}$ Urbanisation, change in lifestyle and high life expectancy are cited as reasons for the increasing prevalence of T2DM. ${ }^{3}$

Bangladesh rank second in T2DM prevalence among SEA countries. Saquib et al (2012) in a meta-analysis of studies conducted between 1995 and 2010, showed continuous increase in pooled T2DM prevalence at the rate of 3.8\% (1995-2000), 5.3\% (2001-2005), and 9.0\% (2006-2010). (4) Currently, 7.1 million people are 
affected with T2DM in Bangladesh, turning it into $10^{\text {th }}$ highest T2DM burden country in the world. ${ }^{1}$ IDF atlas (2015) projects 13.6 million adults in Bangladesh to suffer from T2DM by $2040 .{ }^{1}$

This staggering toll of T2DM and its complications has also increased the total disability adjusted life years (DALYs) by nearly 70\% between 1990 and 2010 in Bangladesh, which is much higher than DALYs attributed to cardiovascular disease and cancer $(25 \%){ }^{5}$ This has led to high economic cost, productivity losses and intangible cost (psychological pain to the family and loved ones), past human suffering. ${ }^{2}$

Strategies to improve diabetes care, thereby mitigating diabetes-related complications are urgently needed. Early screening in high risk groups and proper management is recommended to avoid early complications. A regular audit of diabetes management is an essential step towards the prevention and control. ${ }^{6}$ Periodic evaluations help in assessing the usefulness of measures taken and also depict seriousness of the policies towards global commitment in accordance with the World Health Organization's action plan, en route to achieving long and healthy life. ${ }^{7}$

The DiabCare, a series of cross-sectional observational studies, was started in Europe in 1990s with the collaboration of Novo Nordisk. The primary goal of these studies was to appraise the performance of diabetes care system through participation of large number of patients and clinicians over time. This survey, was not limited to the evaluation of diabetes management, but has also explored the psychological aspect of participating patients. ${ }^{8}$ DiabCare Asia was initiated in 1997 in 6 countries including Bangladesh. ${ }^{9}$ (9) DiabCare Bangladesh 1998 and 2008 have informed healthcare policy and influenced diabetes management programmes in the country. ${ }^{10,11}$ Consistent with previous studies, DiabCare Bangladesh 2012 was performed to describe diabetes management, control and complications. It also evaluated the associated primary and secondary preventive efforts and treatment adherence in patients with T2DM living in Bangladesh.

\section{Methods}

\section{Study design and setting}

An observational, non-interventional, cross-sectional design was used for this study (Universal trial number (UTN): U1111-1137-2729). The study was conducted between June 2013 to September 2013 at 80 secondary care and 20 tertiary care hospitals in Bangladesh. All aspects of the study were conducted in accordance with the Declaration of Helsinki ${ }^{12}$ and the Guidelines for Good Pharmacoepidemiology Practice (GPP), ${ }^{13}$ supervised by study investigators and their deputies. Due to the observational nature of this study, there were no study-specific visits or investigational products and patients were treated according to routine clinical practice at the discretion of the attending physician.

\section{Study participants}

Patients routinely visiting the centre during the study period were screened for eligibility. Before any studyrelated activity, investigators or their deputies gave eligible patients comprehensible oral and written information about the study and obtained informed consent. Adults over the age of 18 years with T2DM on non-pharmacological or pharmacological treatment who had been at the centre for at least one year and had visited the centre within the last 3-6 months were included, if they provided informed consent. Patients who had previously participated in the study, had suspected or confirmed pregnancy or were unable to comply with protocol requirements were excluded from the study. Patients were permitted to withdraw from the study at will at any time. Recruitment and enrolment continued until the target number of patients was reached.

\section{Study endpoints}

The primary endpoint of the study was defined as the proportion of patients with glycosylated haemoglobin (HbA1c) less than $7 \%(53 \mathrm{mmol} / \mathrm{mol})$ at study entry. ${ }^{14}$ (14) This was chosen as the primary endpoint due to the validity of $\mathrm{HbAlc}$ as an indicator of diabetes care. The secondary endpoints were: duration of diabetes, duration and type of treatment, other measures of glycaemic control (fasting plasma glucose (FPG) and post-prandial glucose (PPG), lipid control (total cholesterol, low-density lipoprotein (LDL) cholesterol, high-density lipoprotein (HDL) cholesterol, and fasting triglycerides), presence of known risk factors or diabetes-related complications (dyslipidaemia, hypertension, cardiovascular complications, peripheral vascular disease, diabetic nephropathy, and diabetic eye complications), hypoglycaemia, and treatment adherence. Potential predictor variables including age, gender, body mass index (BMI), diabetes duration, 
hypertension, insulin therapy, use of multiple oral antidiabetic agents (OADs), HbA1c, FPG and performance of self-measurement of blood glucose (SMBG) were analysed for their relationship with various complications.

\section{Data sources and measurement}

Relevant data were collected from patients' medical records and recorded in case report forms (CRFs) designed for this study. Data collected included demography, medical history, complications, eye and foot examinations, diabetes management and most recent laboratory investigations performed within the past one year. Blood samples were collected for $\mathrm{HbA} 1 \mathrm{c}$ measurement. The decision of lab selection, supervision and quality assurance of the centralized measurements were performed by Bangladesh institute of research and rehabilitation in diabetes, endocrine and metabolic disorders (BIRDEM). The blood samples were stored between $2^{\circ} \mathrm{C}$ to $8^{\circ} \mathrm{C}$. HbAlc was measured through venous/capillary blood as per NGSP guidelines (National Glycosylated Standardisation Programme) using BioRad HPLC (High Performance Liquid Chromatography) D 10 or Variant 2 method. Blood samples were stored only for retest purpose and promptly disposed after the completion of the HbA1c analysis. In addition, patients were asked to complete a treatment adherence questionnaire and a hypoglycaemia questionnaire which were administered by investigators or their deputies. The treatment adherence questionnaire included patient adherence to diet, exercise, taking medication as prescribed, performance of SMBG testing and keeping appointments with healthcare professionals. The hypoglycaemia questionnaire assessed symptoms of hypoglycaemia categorised as mild (sweating, dizziness, trembling, tingling in the hands, feet or lips, blurred vision, difficulty in concentrating, palpitations and occasional headache); moderate (odd behaviour such as rudeness or laughter, bad temper or moodiness, aggressive behaviour, confusion); severe (loss of consciousness or needing help from another person); or nocturnal (any symptoms between bedtime and breakfast). The hypoglycaemia questionnaire also assessed patient responses to hypoglycaemia including SMBG testing, snacking, skipping or changing medication doses, visiting hospital and patient concern.

Patient information collected for this study was kept confidential and measures such as encryption were enforced to protect patient identity. Sensitive patient data were kept with investigators according to local regulations regarding personal data protection.

\section{Study size}

The study aimed to enrol a total of 2092 patients from Bangladesh. The sample size was based on published data and consultation with local external experts. The prevalence of cardiovascular disease (CVD) was used as a basis for the study size target because available literature suggests that this is the least prevalent of all diabetic complications and its use confers the maximum possible representativeness to the sample size estimate. Assuming a CVD prevalence of 2\%, a sample of 2092 patients conforms to a $5 \%$ level of significance and $30 \%$ margin of error.

\section{Statistical analysis}

The full analysis set (FAS) included all patients with at least one data point. Missing data was not replaced. The data analysis was performed using SAS, Version [9.2]. Continuous variables were summarised using descriptive statistics: mean \pm standard deviation (SD), median (range), and number missing. Categorical variables were presented as number and percentages $(\%)$. Percentages were based on all patients in the respective patient set regardless of whether they had non-missing values or not.

The influence of potential predictor variables on outcome variables (any diabetes complications) were evaluated by analysis of covariance (ANCOVA) for continuous variables, and by logistic regression for categorical variables. The following predictor variables were assessed separately in the univariate analyses: age, sex, BMI, duration of diabetes, hypertension, insulin therapy, use of multiple OADs, HbA1c, FPG and SMBG (testing done or not done). In a second step, all risk factors were included in the multivariate analysis and a backward stepwise regression method was used to identify significant predictors. Three of the variables age, gender and duration of diabetes were retained in each final model to allow for adjustment of their effects. For continuous predictors, odds ratio estimates for a change in 1 unit were presented with corresponding $95 \%$ confidence intervals and two-sided p-values. For categorical predictors, odds ratio estimates between categories were presented with corresponding 95\% confidence intervals and two-sided p-values.

\section{Results}

\section{Patient characteristics and demographics}

2092 participants with mean age of $51.3 \pm 11.0$ years, $49.8 \%$ male and $50.2 \%$ female, were enrolled in this study. The largest ethnic group was Bangladeshi $(n=2084,99.6 \%)$. Majority of patients belonged to lower 
middle income group $(\mathrm{n}=1156,55.3 \%)$ and had family history of DM $(n=1286,61.5 \%)$. The median duration of T2DM was 6 (min 1: $\max 37)$ years. Approximately one third, $(n=766,36.6 \%)$ of patients led a sedentary lifestyle and mean waist circumference was $87.2 \pm 9.5$ cm (Table I).

Table I. Demographic and General Patient Characteristics

\begin{tabular}{|c|c|}
\hline Variables & $\mathrm{N}=2092$ \\
\hline \multicolumn{2}{|l|}{ Age (years) } \\
\hline Mean (SD) & $51.3(11.0)$ \\
\hline Median & 50.0 \\
\hline (Min, Max) & $(18.0,95.0)$ \\
\hline Male gender $n,(\%)$ & $1041(49.8)$ \\
\hline Female gender $n,(\%)$ & $1051(50.2)$ \\
\hline Duration of diabetes (years) & $7.6(5.4)$ \\
\hline Mean (SD) & 6.0 \\
\hline Median & $(1.0,37.0)$ \\
\hline \multicolumn{2}{|l|}{ (Min, Max) } \\
\hline \multicolumn{2}{|l|}{ Waist circumference $(\mathrm{cm})$} \\
\hline Mean (SD) & $87.2(9.5)$ \\
\hline Median & 86.0 \\
\hline (Min-Max) & $(60.0,130.0)$ \\
\hline \multicolumn{2}{|l|}{ Ethnic groups (n, \%) } \\
\hline Bangladeshi & $2084(99.6)$ \\
\hline Others & $8(0.4)$ \\
\hline \multicolumn{2}{|l|}{ Health Expenses (n, \%) } \\
\hline Government/Community & $23(1.1)$ \\
\hline Self & $2051(98.0)$ \\
\hline Insurance & $75(3.6)$ \\
\hline \multicolumn{2}{|l|}{ Educational status (n, \%) } \\
\hline LCTRW\# & $299(14.3)$ \\
\hline 5 years & $439(21.0)$ \\
\hline 10 years & $724(34.6)$ \\
\hline Graduate & $466(22.3)$ \\
\hline Postgraduate & $164(7.8)$ \\
\hline \multicolumn{2}{|l|}{ Economic status, n (\%) } \\
\hline Low Income Group & $428(20.5)$ \\
\hline Lower Middle Income Group & $1156(55.3)$ \\
\hline Upper Middle Income Group & $454(21.7)$ \\
\hline High Income Group & $54(2.6)$ \\
\hline \multicolumn{2}{|l|}{ Risk Factors (n, \%) } \\
\hline Family History & $1286(61.5)$ \\
\hline Currently smoking & 237 (11.3) \\
\hline Sedentary & $766(36.6)$ \\
\hline
\end{tabular}

All continuous data are presented as mean \pm standard deviation and median (range). Percentage (\%) values calculated from total non-missing. \#LCTRW: Limited Capacity to Read and Write

\section{Glycaemic control}

The mean HbAlc (\%) of the studied population was 8.8 \pm 2.2 . The American Diabetes Association's (15) recommended $\mathrm{HbA} 1 \mathrm{c}$ target of $<7 \%$ was met by approximately one fifth $(22.5 \%$ ) of patients whereas $27.7 \%$ patients had greater than $10.0 \% \mathrm{HbA} 1 \mathrm{c} .41 \%$ patients were evaluated for $\mathrm{HbA} 1 \mathrm{c}$ over the past year and the mean testing frequency was $2.1 \pm 2.1$ times per year. The median FPG and PPG of this cohort was 8.6 and $12.0 \mathrm{mmol} / \mathrm{L}$ respectively. Owing to high inter-subject variability, mean FPG and PPG were skewed. The distribution of patients as per their HbA1c, FPG and PPG is presented in Table II.

\begin{tabular}{|c|c|}
\hline Glycaemic profile & $\mathrm{N}=2092$ \\
\hline \multicolumn{2}{|l|}{ HbA1c $(\%)$} \\
\hline Mean (SD) & $8.8(2.2)$ \\
\hline Median & 8.4 \\
\hline (Min, Max) & $(4.7,14.7)$ \\
\hline \multicolumn{2}{|l|}{ HbA1c quantile (n, \%) } \\
\hline$<7.0 \%(<53 \mathrm{mmol} / \mathrm{mol})$ & $471(22.5)$ \\
\hline $\begin{array}{l}7.0 \% \text { to }<8.0 \%(53 \mathrm{mmol} / \mathrm{mol} \\
\text { to }<64 \mathrm{mmol} / \mathrm{mol})\end{array}$ & $406(19.4)$ \\
\hline $\begin{array}{l}8.0 \% \text { to }<9.0 \%(64 \mathrm{mmol} / \mathrm{mol} \\
\text { to } 75 \mathrm{mmol} / \mathrm{mol})\end{array}$ & $350(16.7)$ \\
\hline $\begin{array}{l}9.0 \% \text { to }<10.0 \%(75 \mathrm{mmol} / \mathrm{mol} \\
\text { to }<86 \mathrm{mmol} / \mathrm{mol})\end{array}$ & 285 (13.6) \\
\hline$\geq 10.0 \%(86 \mathrm{mmol} / \mathrm{mol})$ & $580(27.7)$ \\
\hline \multicolumn{2}{|l|}{ Plasma Glucose } \\
\hline \multicolumn{2}{|l|}{$\mathrm{FPG}(\mathrm{mmol} / \mathrm{L})$} \\
\hline Mean (SD) & $16.0(35.0)$ \\
\hline Median & 8.6 \\
\hline (Min, Max) & $(3.9,360.0)$ \\
\hline Missing (n) & 56 \\
\hline \multicolumn{2}{|l|}{ PPG (mmol/L) } \\
\hline Mean (SD) & $22.3(48.3)$ \\
\hline Median & 12.0 \\
\hline (Min, Max) & $(7.8,360.0)$ \\
\hline Missing (n) & 11 \\
\hline
\end{tabular}

\section{Lipid profile and blood pressure}

The proportion of patients with dyslipidaemia was $56 \%$, however, only $38.8 \%$ were on dyslipidaemia medication. The mean total cholesterol, high density lipoprotein (HDL), low density lipoprotein (LDL) and triglycerides were $5.2 \pm 1.3,1.1 \pm 0.3,3.3 \pm 1.1$ and $2.3 \pm 1.0 \mathrm{mmol} / \mathrm{L}$ respectively. Statins $(85.1 \%)$ and fibrates $(18.9 \%)$ were two most commonly prescribed dyslipidaemia drugs (Table III). 
Table III. Control status of blood pressure and lipids

\begin{tabular}{|c|c|}
\hline \multicolumn{2}{|l|}{ Blood pressure } \\
\hline \multicolumn{2}{|l|}{ Systolic (mmHg) } \\
\hline Mean (SD) & $124.4(12.0)$ \\
\hline Median & 120.0 \\
\hline (Min, Max) & $(80.0,200.0)$ \\
\hline \multicolumn{2}{|l|}{ Diastolic (mmHg) } \\
\hline Mean (SD) & $80.0(6.9)$ \\
\hline Median & 80.0 \\
\hline (Min, Max) & $(40.0,110.0)$ \\
\hline Hypertension $^{\mathrm{a}}(\mathrm{n}, \%)$ & $1180(56.4)$ \\
\hline Hypertensive medication (n, \%) & $1062(50.8)$ \\
\hline \multicolumn{2}{|l|}{ Anti-hypertensive medication (n, \%) } \\
\hline ACE inhibitor & $328(30.9)$ \\
\hline $\mathrm{ARB}$ & $377(35.5)$ \\
\hline Alpha Blocker & $43(4.0)$ \\
\hline Alpha-2-Agonist & $50(4.7)$ \\
\hline Beta-blocker & $304(28.6)$ \\
\hline $\mathrm{Ca} 2+$ Channel Antagonist & $267(25.1)$ \\
\hline Diuretics & $186(17.5)$ \\
\hline Other & $45(4.2)$ \\
\hline \multicolumn{2}{|l|}{ Lipids } \\
\hline \multicolumn{2}{|l|}{ Total Cholesterol (mmol/L) } \\
\hline Mean (SD) & $5.2(1.3)$ \\
\hline Median & 5.2 \\
\hline Min, Max & $2.6,10.3$ \\
\hline Missing (n) & 957 \\
\hline \multicolumn{2}{|l|}{ HDL Cholesterol (mmol/L) } \\
\hline Mean (SD) & $1.1(0.3)$ \\
\hline Median & 1.0 \\
\hline (Min, Max) & $(0.1,3.4)$ \\
\hline Missing (n) & 957 \\
\hline \multicolumn{2}{|l|}{ LDL Cholesterol (mmol/L) } \\
\hline Mean (SD) & $3.3(1.1)$ \\
\hline Median & 3.2 \\
\hline (Min, Max) & $(1.3,7.1)$ \\
\hline Missing (n) & 957 \\
\hline \multicolumn{2}{|l|}{ Fasting Triglycerides $(\mathrm{mmol} / \mathrm{L})$} \\
\hline Mean (SD) & $2.3(1.0)$ \\
\hline Median & 2.1 \\
\hline (Min, Max) & $(1.1,6.8)$ \\
\hline Missing (n) & 957 \\
\hline Dyslipidaemia ${ }^{b}$ & $1171(56.0)$ \\
\hline Missing (n) & 27 \\
\hline Dyslipidaemia medication (n, \%) & $811(38.8)$ \\
\hline \multicolumn{2}{|l|}{ Dyslipidaemia medication (n, \%) } \\
\hline Statin & $690(85.1)$ \\
\hline Fibrate & $153(18.9)$ \\
\hline Niacin & $1(0.1)$ \\
\hline Ezetimibe & $8(1.0)$ \\
\hline Other & $11(1.4)$ \\
\hline
\end{tabular}

All continuous data are presented as mean \pm standard deviation and median (range). Percentage (\%) values calculated from total non-missing.
${ }^{a}$ Hypertension was defined as patients currently taking medication for hypertension, or systolic blood pressure (SBP) $\geq 140 \mathrm{mmHg}$, or diastolic blood pressure (DBP) $\geq 90 \mathrm{mmHg}$. b Dyslipidaemia was defined as patients currently taking medication for dyslipidaemia or presented with low density lipoprotein (LDL) cholesterol $>2.6 \mathrm{mmol} / \mathrm{L}$, or high density lipoprotein (HDL) cholesterol $<1.0 \mathrm{mmol} / \mathrm{L}$ in males and $<1.3$ $\mathrm{mmol} / \mathrm{L}$ in females, or triglycerides $>1.7 \mathrm{mmol} / \mathrm{L}$.

$56.4 \%$ patients were hypertensive with only $50.8 \%$ taking anti-hypertensive medication. The mean systolic and diastolic blood pressure was $124.4 \pm 12.0$ and $80.0 \pm 6.9 \mathrm{mmHg}$ respectively. The most frequently used anti-hypertensive medications were angiotensin-II receptor blockers (ARBs) (35.5\%) and angiotensinconverting enzyme (ACE) inhibitors (30.9\%) (Table III). Duration of diabetes, higher BMI and higher HbAlc were predictive for both hypertension and dyslipidemia.

Table IV. Diabetes-related complications

\begin{tabular}{lc}
\hline Eye complications (n, \%) & $454(21.7)$ \\
Screened for eye disease within the & $861(41.2)$ \\
last two years & \\
Background diabetic retinopathy & $183(8.7)$ \\
non-proliferative & \\
History of photocoagulation & $30(1.4)$ \\
Proliferative diabetic retinopathy & $72(3.4)$ \\
Severe vision loss & $101(4.8)$ \\
Macular oedema & $20(1.0)$ \\
Cataract & $189(9.0)$ \\
Cardiovascular complications (n, \%) & $352(16.8)$ \\
Myocardial infarction & $113(5.4)$ \\
Angina & $170(8.1)$ \\
Peripheral vascular disease & $84(4.0)$ \\
Stroke & $50(2.4)$ \\
Congestive Heart Failure & $22(1.1)$ \\
Atrial fibrillation & $2(0.1)$ \\
Left Ventricular Hypertrophy & $24(1.1)$ \\
History of a revascularisation procedure & $19(0.9)$ \\
(e.g. CABG) & \\
Renal complications (n, \%) & $280(13.4)$ \\
Screened for renal disease within the & $723(34.6)$ \\
last two years & \\
Microalbuminuria & $210(10.0)$ \\
Gross proteinuria & $83(4.0)$ \\
End-stage renal disease & $12(0.6)$ \\
Dialysis & $4(0.2)$ \\
Foot complications (n, \%) & $239(11.4)$ \\
Active ulcer & $114(5.4)$ \\
Healed ulcer & $118(5.6)$ \\
History of amputation & $56(2.7)$ \\
Erectile dysfunction (n, \%) & $164(15.8)$ \\
Peripheral neuropathy (n, \%) & $815(39.0)$ \\
\hline Al &
\end{tabular}

All continuous data are presented as mean \pm standard deviation and median (range). Percentage (\%) values calculated from total non-missing. 
Table-V. Results of multivariate analyses to identify independent predictors of selected diabetes complications

\begin{tabular}{|c|c|c|c|c|}
\hline \multirow{2}{*}{$\begin{array}{l}\text { Independent } \\
\text { variables }\end{array}$} & \multicolumn{4}{|c|}{ Adjusted odds ratio $(95 \% \mathrm{CI}) \mathrm{p}$-value } \\
\hline & CardiovascularComplications* & PeripheralVascular Disease & DiabetesNephropathy'! & Eye Complications $\ddagger$ \\
\hline Age [in years] & $1.04(1.03,1.05)<0.001$ & $1.01(0.99,1.03) 0.406$ & $1.02(1.01,1.04)<0.001$ & $1.05(1.04,1.06)<0.001$ \\
\hline Gender [Male vs & $1.37(1.08,1.73) 0.010$ & $1.64(1.06,2.53) 0.027$ & $0.83(0.64,1.06) 0.139$ & $0.91(0.73,1.13) 0.405$ \\
\hline \multicolumn{5}{|l|}{ Female] } \\
\hline Duration of diabetes & $1.03(1.01,1.05) 0.007$ & $1.01(0.97,1.05) 0.740$ & $1.05(1.02,1.07)<0.001$ & $1.05(1.03,1.07)<0.001$ \\
\hline \multicolumn{5}{|l|}{ [inyears] } \\
\hline HbA1c value $[\%]$ & $1.09(1.03,1.15) 0.003$ & - & - & $1.07(1.02,1.13) 0.007$ \\
\hline FPG value $[\mathrm{mmol} / \mathrm{L}]$ & ] $0.99(0.99,1.00) 0.012$ & - & $0.99(0.99,1.00) 0.010$ & $0.99(0.99,1.00) 0.004$ \\
\hline Hypertension $^{\S}$ & $2.66(2.04,3.48)<0.001$ & - & $2.02(1.53,2.67)<0.001$ & - \\
\hline
\end{tabular}

*Cardiovascular complications: myocardial infarction, peripheral vascular disease, congestive heart failure, left ventricular hypertrophy, angina, stroke/transient ischaemic attack, atrial fibrillation or history of revascularisation procedure.

'!Diabetic nephropathy: Microalbuminuria, gross proteinuria, end-stage renal disease or dialysis.

†Eye complications: Non-proliferative retinopathy, proliferative diabetic retinopathy, macular oedema, history of photocoagulation, severe vision loss or cataract.

$\S$ Hypertension: SBP e"140 or DBP e"90 mmHg, or on medications for hypertension

|Multiple OADs: At least 2 oral medications (except herbal medicine).

For continuous variables, the results are for per unit increase in variable.

\section{Diabetes-related complications}

The most commonly seen diabetes related complications were peripheral neuropathy $(39.0 \%)$ and eye complications $(21.7 \%)$. The proportion of patients with cardiovascular (CV), renal, foot complications, and erectile dysfunction were $16.8 \%, 13.4 \%, 11.4 \%$ and $15.8 \%$ respectively. Approximately $34.6 \%$ had been screened for renal complications in past two years. The most commonly encountered renal complication was microalbuminuria (10.0\%) followed by gross proteinuria $(4.0 \%)$. Cataract $(9.0 \%)$ and nonproliferative diabetic retinopathy $(8.7 \%)$ were the most common eye complications. Angina was the most frequently reported $\mathrm{CV}$ complication and $2.7 \%$ of T2DM patients had amputation. (Table-IV)

Duration of T2DM and age were strongly correlated with selected diabetes complications including cardiovascular (Adjusted OR=1.03 $\mathrm{p}=0.007 \& 1.04$ $\mathrm{p}<0.001$ ), renal (Adjusted OR $=1.05 \mathrm{p}<0.001 \& 1.02$ $\mathrm{p}<0.001$ ) and eye complications (Adjusted $\mathrm{OR}=1.05$ $\mathrm{p}<0.001 \& 1.05 \mathrm{p}<0.001$ respectively]. Hypertension was predictive of $\mathrm{CV}$ complications and diabetic nephropathy ( $p<0.001$ and $p<0.001$, respectively). Higher HbA1c showed greater odds of developing CV and eye complications (Table-V).

\section{Diabetes management}

Majority of patients $(92.3 \%)$ were receiving treatment for diabetes. $58.0 \%$ patients were on insulin treatment (either alone or combination with OAD). The most commonly prescribed OADs were metformin (81.8\%) and sulphonylureas (52.6\%). The mean duration of OAD treatment and insulin therapy was $5.9 \pm 4.4$ and $4.4 \pm 4.4$ years respectively.

Premix twice daily (83.4\%) was the most commonly prescribed insulin regimen. Basal+OAD and basal-bolus regimen were used by $2.4 \%$ and $9.9 \%$ patients respectively. The mean number of injections per day and mean total daily insulin dose was $2.2 \pm 0.7$ and $34.4 \pm 14.7$ IU respectively. In $80.6 \%$ patients, insulin was administered through vial or syringe, while $19.4 \%$ patients used Pen devices. The pharmacological treatments are summarised in Table VI. 


\begin{tabular}{|c|c|}
\hline \multicolumn{2}{|l|}{ Duration of diabetes [years] } \\
\hline $\mathrm{n}$ & 2092 \\
\hline Mean (SD) & $7.6(5.4)$ \\
\hline Median & 6.0 \\
\hline (Min, Max) & $(1.0,37.0)$ \\
\hline Duration of treatment [years]n & 2092 \\
\hline Mean (SD) & $7.1(5.2)$ \\
\hline Median & 6.0 \\
\hline (Min, Max) & $(1.0,36.0)$ \\
\hline Duration of OAD treatment [years]n & 1943 \\
\hline Mean (SD) & $5.9(4.4)$ \\
\hline Median & 5.0 \\
\hline (Min, Max) & $(0.0,36.0)$ \\
\hline Missing & 149 \\
\hline \multicolumn{2}{|l|}{ Duration of insulin treatment [years] } \\
\hline $\mathrm{n}$ & 1235 \\
\hline Mean (SD) & $4.4(4.4)$ \\
\hline Median & 3.0 \\
\hline (Min, Max) & $(0.0,33.0)$ \\
\hline Missing & 857 \\
\hline \multicolumn{2}{|c|}{ Current antidiabetic (oral/non-insulin injectables) therapy, $\mathrm{n}(\%$} \\
\hline Yes & $1930(92.3)$ \\
\hline No & $162(7.7)$ \\
\hline \multicolumn{2}{|l|}{ Current insulin therapy, $\mathrm{n}(\%)$} \\
\hline Yes & $1214(58.0)$ \\
\hline No & $878(42.0)$ \\
\hline \multicolumn{2}{|l|}{ Diabetes Treatment, OAD (n, \%) } \\
\hline Metformin & $1579(81.8)$ \\
\hline Sulphonylurea & $1015(52.6)$ \\
\hline Thiazolidinedione & $206(10.7)$ \\
\hline Glucosidase Inhibitor & $68(3.5)$ \\
\hline Glinide & $35(1.8)$ \\
\hline DPP4 Inhibitor & $286(14.8)$ \\
\hline GLP-1 Analogue & $16(0.8)$ \\
\hline Herbal/Traditional Medicine & $15(0.8)$ \\
\hline Insulin & $1214(58.0)$ \\
\hline \multicolumn{2}{|l|}{ Insulin Delivery (n, \%) } \\
\hline Pen Device & $236(19.4)$ \\
\hline Vial/Syringe & $978(80.6)$ \\
\hline \multicolumn{2}{|l|}{ Insulin Regimens (n, \%) } \\
\hline Basal + OAD & $29(2.4)$ \\
\hline Premix OD & $19(1.6)$ \\
\hline Premix BD & $1013(83.4)$ \\
\hline Premix TID & $32(2.6)$ \\
\hline
\end{tabular}

Basal-Bolus

$120(9.9)$

Total Daily Insulin Dose (IU/d)

All Regimens

Mean (SD)

$34.4(14.7)$

Median

32.0

(Min, Max)

$(6.0,108.0)$

All continuous data are presented as mean \pm standard deviation and median (range). Percentage (\%) values calculated from total non-missing.

\section{Treatment adherence}

A large proportion of patients were non-adherent to clinical recommendations regarding diet (52.3\%), exercise $(65.4 \%)$ and self-testing (74.5\%). Around one third $(32.2 \%)$ of patients were non-compliant to their prescribed medications and even substantial proportion of patients $(51.0 \%)$ did not completely adhere to scheduled appointments with healthcare professionals.

\section{Hypoglycaemia}

The incidences of mild, moderate, severe and nocturnal hypoglycaemia reported within the past three months were $33.5 \%, 9.3 \%, 3.0 \%$ and $8.8 \%$, respectively (Table VII). More than half of patients $(54.7 \%)$ indicated their concerns about hypoglycaemia. Among patients who experienced hypoglycaemia, $80.3 \%$ either never checked their blood glucose or checked occasionally. Small proportion of patients $(9.3 \%)$ measured their blood glucose frequently for a few days following an episode. Most of the patients (82.7\%) never visited a hospital, or visited on rare instances after hypoglycaemic episodes. $45.3 \%$ had performed SMBG over the past year, at a median frequency of 2.0 (1.0"30.0) times in the past month. In addition, 70.2\% patients started snacking between meals and even a substantial proportion of patients $(31.6 \%)$ skipped or reduced their diabetes medications because of hypoglycaemia.

\section{Quality of life}

Though patients' responses to the EQ-5D questionnaire were collected, the use of a modified version of the EQ$5 \mathrm{D}$ form violated the user agreement with the instrument owner (EuroQol group) and rendered the data unsuitable for analysis. 
Table VIII. Hypoglycaemia questionnaire

Hypoglycaemia symptoms in the last 3 months

Mild 'hypo' - Sweating, dizziness, trembling, tingling in the hands, feet or lips, hunger, blurred

vision, difficulty in concentrating, palpitations and occasional headache.

Moderate 'hypo' - Odd behaviour such as rudeness or laughter (appearing drunk when you are not), bad temper or moodiness, aggressive

behaviour, confusion.

Severe 'hypo' - Unconsciousness or help from someone else.

Nocturnal 'hypo' - Symptoms between bedtime and breakfast.
$\mathrm{N}(\%)$

$701(33.5)$

Number of episodes

Mean (SD)

Median

(Min,Max)

$\mathrm{N}(\%)$

$195(9.3)$

Number of episodes

Mean (SD)

Median

1.0

(Min,Max)

$\mathrm{N}(\%)$

$63(3.0)$

Number of episodes

Mean (SD)

Median

(Min,Max)

$\mathrm{N}(\%)$

Number of episodes

$\begin{array}{cc}\text { Mean (SD) } & 1.6(1.2) \\ \text { Median } & 1.0 \\ \text { (Min,Max) } & (1.0,12.0)\end{array}$

All continuous data are presented as mean \pm standard deviation and median (range).

\section{Discussion}

DiabCare Bangladesh 2012 more competently describes diabetes care currently being delivered, the challenges associated with improving care and the future role of diabetes prevention. It has enrolled relatively higher patients (2092) as compared to previous DiabCare studies. ${ }^{10}$, The mean age of the patients (51.3 years) is consistent with previous DiabCare and other studies conducted in Bangladesh. ${ }^{10,16}$ The patients in this study had relatively shorter disease duration (6 years) as compared to DiabCare 2008 (7.9 years). Greater proportion of patients with family history of diabetes $(61.5 \%$ vs. $52.8 \%)$ and smoking habits ( $11.3 \%$ vs. $8.2 \%)$ has been observed as compared to DiabCare 2008 study. The increasing incidence of risks emphasise the need of primary prevention programs for T2DM management in Bangladesh.
Using multiple diagnostic criteria, as assessed by centralized HbA1c, FPG and PPG measurements, DiabCare Bangladesh 2012 showed unsatisfactory glycaemic control in majority of patients surveyed. The mean $\mathrm{HbA} 1 \mathrm{c}$ of $8.4 \%$ is similar to two previous DiabCare studies of $2008(8.6 \%)$ and 1998 $(7.9 \%) .{ }^{10,11}$ Islam et al (2015) also recently demonstrated mean $\mathrm{HbA} 1 \mathrm{c}$ of $8.3 \%$ in 515 T2DM patients. ${ }^{17}$ The proportion of patients with poor glycaemic control (HbA1c e"7.0\%) within this cohort is comparable (77.5\%) to the DiabCare $2008(76.9 \%)$, but greater than that of 1998 study $(63.3 \%) .{ }^{10,11}$ The median FPG is also consistent with DiabCare 2008 study $(8.4 \pm 2.7 \mathrm{mmol} / \mathrm{L}) .{ }^{10}$ Sultana et al found mean FPG levels of $8.9 \pm 3.6 \mathrm{mmol} / \mathrm{L}$ in a prospective study from a tertiary care setting $(\mathrm{n}=140)$ in Bangladesh. ${ }^{16}$ 
Suboptimal glycaemic control is probably attributed to low frequency of $\mathrm{HbA} 1 \mathrm{c}$ testing, life style modification and treatment compliance. ${ }^{14}$ Approximately $59 \%$ of patients have not evaluated $\mathrm{HbA} 1 \mathrm{c}$ in the past year. Patient responses to the hypoglycaemia questionnaire also showed their non seriousness in monitoring blood glucose. Further, high proportion of patients did not adhere to treatment-related advice and a substantial proportion did not adhere to their prescribed regimens. Over one third of patients accustomed to a sedentary lifestyle. Rising life expectancies coupled with 'unhealthy' ageing and sedentary lifestyle present a new set of challenges in developing countries. Hence, policies focusing on prevention should emphasise the need to promote frequent $\mathrm{HbA} 1 \mathrm{c}$ testing, improve patient adherence and lifestyle modification.

Microvascular and macrovascular complications in the current and 2008 DiabCare demonstrated neuropathy symptoms $(39.0 \%$ vs $31.7 \%)$, microalbuminuria ( $10.0 \%$ vs $15.7 \%)$, cataract $(9.0 \%$ vs $12.9 \%)$, myocardial infarction (5.4 vs $5.2 \%$ ), active ulcer/ gangrene $(5.4 \%$ vs $2.9 \%)$, cerebral stroke $(2.4 \%$ vs $2.2 \%)$, and leg amputation (2.7\% vs $1.2 \%)$. DiabCare Bangladesh 2012 has observed higher incidences of peripheral neuropathy, active ulcer/gangrene and leg amputation. ${ }^{10}$ Sultana et al (2013) reported 21\% cataract, $14 \%$ nephropathy, 35\% neurological problems and $6 \%$ kidney problems in T2DM patients in Bangladesh. ${ }^{16}$ Duration of diabetes has emerged as a significant risk for both micro- and macrovascular complications, which is similar to other reported studies. ${ }^{18,19}$ Kibriya et al. (1998) also demonstrated the correlation of longer duration of diabetes with neuropathy, nephropathy and retinopathy. ${ }^{11}$

Proportion of patients using OADs has increased $(92.3 \%)$ in the current DiabCare compared to that of $2008(89.1 \%)$ and 1998 (65.9\%) respectively. ${ }^{10,11}$ Biguanides $(81.8 \%)$ followed by sulphonylureas $(52.6 \%)$ are the most commonly used OADs in the current DiabCare, whereas the trend of sulphonylurea $(55.8 \%)$ prescription was more than biguanides (54.2\%) in 2008. Recently Ahmed et al (2016) has also revealed metformin as the single most prescribed
OADs. Increasing prescription of metformin in patients with T2DM in Bangladesh is attributed to its negligible risk of hypoglycaemia and potential cardiovascular and metabolic benefit as compared to sulphonylureas. ${ }^{21}$

$58 \%$ of patients are insulin users in the current study which is almost three-fold as compared to DiabCare Bangladesh 1998 study (21.8\%) and higher than DiabCare 2008 (42.7\%). ${ }^{10,11}$ The frequency of insulin pen user has increased from $13.5 \%$ in 2008 to $19.4 \%$ patients in the current study. Premix twice daily (83.4\%) has remained the most commonly prescribed insulin regimen (DiabCare 2008; 82.8\%). ${ }^{10}$ Increased frequency of insulin users reflects more aggressive management strategy adopted in Bangladesh in T2DM patients as recommended by previous DiabCare studies. The United Kingdom Prospective Diabetes Studies (UKPDS) has also showed that the control of glycaemia was maintained in $50 \%$ of T2DM patients, who had been getting insulin treatment for over 6 years. ${ }^{22}$ However still a large proportion of patients have not met target $\mathrm{HbA} 1 \mathrm{c}$ or blood glucose levels in the current DiabCare.

Higher proportion of T2DM patients had hypertension (56.4\%) as compared to 2008 and 1998 study (47\% vs. $35.8 \%)$. However, proportion of dyslipidemia is consistent with DiabCare 1998 and 2008 Bangladesh studies. ${ }^{10,11}$ Results also showed older age, HbA1c, and FPG to be associated with higher odds of dyslipidaemia and hypertension. Efforts to control blood glucose levels as well as cardiovascular risk factors such as lipids or hypertension is imperative for successful management of T2DM.

The findings of this study need to be interpreted in light of the study limitations. Firstly, due to the cross-sectional observational nature of the study, it is not possible to completely exclude the effect of selection bias and also to draw conclusions on the impact of treatment. Secondly, as all centres offered specialised diabetes care services, patients attending these centres, who were eligible for enrolment in the study, may not be representative of the country as a whole. Thirdly, data on treatment adherence and hypoglycaemia were selfreported, and the estimates may have been subject to recall bias. Further, due to the retrospective 
collection of laboratory findings aside from $\mathrm{HbA} 1 \mathrm{c}$, it was not possible to fully assess the status of glycaemic and lipid control in the entire study population. Nevertheless, the relatively large numbers of patients with available laboratory results do allow for relative valid observations to be drawn.

\section{Conclusion}

DaibCare 2012 has emphasized that still a large proportion of patients with T2DM in Bangladesh have unsatisfactory glycaemic and metabolic control, high prevalence of complications and suboptimal treatment adherence. The complexities and intricacies of providing quality diabetes care are challenging. Understanding the importance of comprehensive care and implementing the quality measures will help track progress and guide improvement. The study supports the current efforts of healthcare professionals towards diabetes care to bring down $\mathrm{HbA}_{1} \mathrm{C}<7 \%$ among Diabetics and demand aggressive strategies for high risk patients to prevent Diabetes. Improving awareness among health professionals and diabetic subjects with intensive education programs is also recommended.

\section{Acknowledgements}

Authors acknowledge WorkSure India for providing medical writing assistance.

\section{Conflicts of interest}

All authors declare no conflict of interests.

\section{References}

1. International Diabetes Federation. IDF Diabetes eB, Belgium: International Diabetes Federation, 2015. http:// www.diabetesatlas.org.

2. Engelgau MM, Narayan KM, Saaddine JB, Vinicor F. Addressing the burden of diabetes in the 21st century: better care and primary prevention. Journal of the American Society of Nephrology : JASN. 2003 Jul;14(7 Suppl 2):S88-91.

3. Cheema A, Adeloye D, Sidhu S, Sridhar D, Chan KY. Urbanization and prevalence of type 2 diabetes in Southern Asia: A systematic analysis. Journal of global health. 2014 Jun;4(1):010404.

4. Saquib N, Saquib J, Ahmed T, Khanam MA, Cullen MR. Cardiovascular diseases and type 2 diabetes in Bangladesh: a systematic review and meta-analysis of studies between 1995 and 2010. BMC public health. 2012;12:434.
5. Low WY LY, Samy AL. Non-communicable diseases in the Asia-Pacific region: Prevalence, risk factors and communitybased prevention. Int J Occup Med Environ Health 2015;28:20-6.

6. King H, Aubert RE, Herman WH. Global burden of diabetes, 1995-2025: prevalence, numerical estimates, and projections. Diabetes care. 1998 Sep;21(9):1414-31.

7. World health organization. Action plan for the prevention and control of noncommunicable diseases in South-East Asia -

8. Attali JR. [DiabCare tools for the control of permanent improvement of the quality of care in diabetes]. Diabete \& metabolisme. 1993 Dec;19(5 Suppl):533-7.

9. Raheja BS, Kapur A, Bhoraskar A, Sathe SR, Jorgensen LN, Moorthi SR, et al. DiabCare Asia-India Study: diabetes care in India - current status. The Journal of the Association of Physicians of India. $2001 \mathrm{Jul} ; 49: 717-22$.

10. Latif ZA, Jain A, Rahman MM. Evaluation of management, control, complications and psychosocial aspects of diabetics in Bangladesh: DiabCare Bangladesh 2008. Bangladesh Medical Research Council bulletin. 2011 Apr;37(1):11-6.

11. Kibriya M, Mahtab H. Micro-Vascular complications in type2 diabetes in Bangladesh: The diabcare-Asia, Bangladesh project. Diabetes Research and Clinical Practice. 2000;50:135-6.

12. World Medical Association. Declaration of Helsinki. Ethical principles for medical research involving human subjects. Seoul: 59th WMA General Assembly; 2008.

13. ISPE (International Society for Pharmacoepidemiology). Guidelines for good pharmacoepidemiology practices (GPP). 2007 April.

14. Standards of medical care in diabetes - 2014. Diabetes care. 2014 Jan;37 Suppl 1:S14-80.

15. American Diabetes Association. Standards of medical care in diabetes-2014. . Diabetes Care 2014;37(Suppl 1): S14-S80.

16. Sultana Z, Ali ME, Akhtar MA, Uddin MS, Haque MM. A Study of Evaluation for the Management of Diabetes in Bangladesh. 2013.

17. Islam SM, Alam DS, Wahiduzzaman M, Niessen LW, Froeschl G, Ferrari U, et al. Clinical characteristics and complications of patients with type 2 diabetes attending an urban hospital in Bangladesh. Diabetes \& metabolic syndrome. 2015 JanMar;9(1):7-13.

18. Harris M, Eastman R, Cowie C. Symptoms of sensory neuropathy in adults with NIDDM in the U.S. population. Diabetes care. 1993 Nov;16(11):1446-52. 
19. Flynn MD, O’Brien IA, Corrall RJ. The prevalence of autonomic and peripheral neuropathy in insulin-treated diabetic subjects. Diabetic medicine : a journal of the British Diabetic Association. 1995 Apr;12(4):310-3.

20. Ahmed Z, Hafez MA, Bari MA, Akhter J. Pattern of antidiabetic drugs prescribed in a tertiary care hospital of Bangladesh. International journal of basic and clinical pharmacology. 2016 Jan-Feb;5(1):6-12.
21. Scheen AJ. Dipeptidylpeptidase-4 (DPP-4) inhibitors are favourable to glucagon-like peptide-1 (GLP-1) receptor agonists: yes. European journal of internal medicine. 2012 Mar;23(2):126-31.

22. King P, Peacock I, Donnelly R. The UK prospective diabetes study (UKPDS): clinical and therapeutic implications for type 2 diabetes. British journal of clinical pharmacology. 1999 Nov;48(5):643-8. 